\title{
DESAFIOS DOS ESTUDANTES TRABALHADORES DE CURSOS DE ADMINISTRAÇÃO, CONTABILIDADE E DIREITO DE UMA INSTITUIÇÃ̃O DE ENSINO SUPERIOR DO OESTE CATARINENSE
}

\author{
Augusto Fischer, Universidade do Oeste de Santa Catarina (UNOESC) \\ augusto.fischer@unoesc.edu.br \\ Ardinet Rover, Universidade do Oeste de Santa Catarina (UNOESC) \\ ardinete.rover@unoesc.edu.br \\ Tania Maria dos Santos Nadori, Universidade do Oeste de Santa Catarina (UNOESC) \\ tania.nodari@unoesc.edu.br \\ Hendy Luci Callegari de Lima, Universidade do Oeste de Santa Catarina (UNOESC) \\ hendyluci2010@hotmail.com
}

\section{RESUMO}

Este estudo teve como objetivo analisar os desafios de estudantes de Administração, Contabilidade e Direito de uma IES do Oeste de Santa Catarina. O estudo caracteriza-se pela abordagem qualitativa e quantitativa da pesquisa, e como pesquisa exploratória e descritiva quanto aos fins, com a aplicação dos procedimentos de levantamento tipo survey. A população é constituida de 5.359 estudantes do primeiro semestre de 2019 nos três cursos, para os quais foi enviado questionário semiestruturado por meio do Google docs, recebendo-se 227 respostas. Quanto ao perfil, 95\% dos estudantes trabalham, são predominantemente do sexo feminino, têm até 24 anos, residem com familiares e têm renda de até R\$ $1.499,00$. Os estudantes dedicam até quatro horas diárias aos estudos e buscam, por meio destes, a formação profissional, melhores oportunidades de trabalho, qualidade de vida, reconhecimento pessoal e prestígio social. A independência financeira é o principal motivo que os leva a conciliarem os estudos com o trabalho. As dificuldades percebidas são típicas entre os estudantes do contexto contemporâneo. Quanto às condições financeiras, os estudantes são indiferentes ou percebem ter poucas dificuldades, situação decorrente do apoio familiar, da renda do trabalho e de bolsas de estudo. As expectativas com os cursos frequentados são atendidas e há satisfação com relação a eles. Contudo, também são apontadas insatisfações com o rendimento escolar e uma minoria cujas expectativas não são atendidas e que não está satisfeita com o curso frequentado, o que indica lacunas para aperfeiçoamento dos processos de ensinoaprendizagem.

Palavras-chave: Estudante-trabalhador, Desafios estudantis, Ensino superior.

Data de recebimento: 09/05/2020

Data do aceite de publicação: 28/12/2020

Data da publicação: 30/12/2020 


\title{
CHALLENGES OF WORKING STUDENTS IN ADMINISTRATION, ACCOUNTING AND LAW COURSES OF A HIGHER EDUCATION INSTITUTION IN WEST OF SANTA CATARINA
}

\author{
Augusto Fischer, Universidade do Oeste de Santa Catarina (UNOESC) \\ augusto.fischer@unoesc.edu.br \\ Ardinet Rover, Universidade do Oeste de Santa Catarina (UNOESC) \\ ardinete.rover@unoesc.edu.br \\ Tania Maria dos Santos Nadori, Universidade do Oeste de Santa Catarina (UNOESC) \\ tania.nodari@unoesc.edu.br \\ Hendy Luci Callegari de Lima, Universidade do Oeste de Santa Catarina (UNOESC) \\ hendyluci2010@hotmail.com
}

\begin{abstract}
This study aimed to analyze the challenges of Administration, Accounting and Law students at a higher education institution in the West of Santa Catarina. The study is characterized by the qualitative and quantitative approach of the research, and as exploratory and descriptive research as to the purposes, with application of survey procedures. The population consists of 5,359 students from the first semester of 2019 in the three courses, to which a semi-structured questionnaire was sent via Google docs, and 227 responses were received. Regarding the profile, 95\% of students are working, are predominantly female, are up to 24 years old, live with family members and have an income of up to $\mathrm{R} \$ 1,499.00$. Students dedicate up to four hours a day to studying and seek through the studies the professional formation, better work opportunities, quality of life, personal recognition, and social prestige. Financial independence is the main reason for them to reconcile studies with work. The perceived difficulties are typical among students in the contemporary context. Regarding financial conditions, the students are indifferent or perceive to have few difficulties, a situation resulting from family support, income from work and scholarships. Expectations with the courses attended are met and there is satisfaction with them. However, dissatisfactions with school performance and a minority whose expectations are not met and who are not satisfied with the course attended are also pointed out, which indicates gaps in the improvement the teachinglearning processes.
\end{abstract}

Keywords: Student-worker, Student challenges, High teaching.

\section{INTRODUÇÃO}

No contexto contemporâneo e com as transformações socioeconômicas provocadas principalmente pela globalização, o mercado de trabalho passou a exigir indivíduos mais produtivos, críticos e participantes na vida social, e, assim, muitos trabalhadores tornaram-se também estudantes. Significativa parcela dos estudantes de nível superior, sobretudo em instituições de ensino superior (IES) particulares, incluídas as universidades comunitárias, trabalha e estuda, submetendo-se à dupla jornada de atividades. Estudos de diversos países evidenciaram que entre 53 e $89 \%$ dos estudantes universitários têm jornadas médias de trabalho de 15 horas semanais ou mais (NIQUINI et al., 2015). 


\section{DESAFIOS DOS ESTUDANTES TRABALHADORES DE CURSOS DE ADMINISTRAÇÃO, CONTABILIDADE E DIREITO DE UMA INSTITUIÇÃO DE ENSINO SUPERIOR DO OESTE CATARINENSE}

Embora se atribuam definições distintas para estudantes trabalhadores e trabalhadores estudantes (FURLANI, 1998; MODESTO, 2012), neste projeto se utilizará a definição de estudante trabalhador. Esse sujeito é o estudante de curso superior que, além de estudar, está inserido no mercado de trabalho (FURLANI, 1998; MODESTO, 2012). É tipicamente estudante de curso noturno, em universidade particular, uma vez que essas instituições têm maior oferta de vagas nesse turno. Esse turno é precisamente uma lacuna que as universidades públicas não têm suprido, sobretudo as instituições federais e estaduais de ensino superior, que se concentram na oferta de vagas para o turno diurno (OLIVEIRA; BITTAR; LEMOS, 2010).

As razões para esses estudantes se dedicarem de forma intercalada ao trabalho e aos estudos concentram-se principalmente na busca de uma formação compreendida por um diploma como meio para melhorarem suas condições de vida (BITTAR; ALMEIDA; VELOSO, 2008; PELEIAS et al., 2008). Porém, essas razões não se limitam às condições socioeconômicas. Muitos estudantes trabalham para manter seus estudos, mas outros, por sua vez, objetivam o crescimento profissional (MODESTO, 2012).

Estudantes trabalhadores estão sujeitos a desafios peculiares aos estudos, em razão do compartilhamento de tempo entre trabalho e estudo (ABRANTES, 2012; FURLANI, 1998; PELEIAS et al., 2008; VARGAS; PAULA, 2013). Para Carrano (2002), os estudantes universitários, principalmente aqueles que precisam conciliar suas atividades profissionais com os estudos, deparam-se com inúmeras dificuldades.

Predominantemente, os estudantes trabalhadores frequentam os cursos noturnos, e essa condição exige jornada estendida, acentuando o cansaço físico decorrente da jornada normal (MENDES, 1986 apud TERRIBILI FILHO; QUAGLIO, 2005).

Entre os estudantes que frequentam a IES objeto deste projeto, localizada no Oeste Catarinense, 73,8\% dos estudantes da área das Ciências Sociais Aplicadas, 60,6\% dos estudantes da área da Saúde, e 71\% dos estudantes da área de Engenharias e Exatas estudam e trabalham. Além de desafios comuns para a conciliação entre trabalho e estudo, muitos desses estudantes residem em outras cidades, algumas vezes, mais de 50 quilômetros distantes das unidades de ensino. Ante o exposto, levanta-se a seguinte questão de pesquisa: quais são os desafios dos estudantes trabalhadores de uma IES do Oeste Catarinense?

Este projeto de pesquisa se propõe a analisar os desafios de estudantes trabalhadores de graduação nos Cursos de Administração, Contabilidade e Direito de uma IES localizada no Oeste Catarinense. Para tal, seu objetivo geral é analisar os desafios de estudantes trabalhadores de administração, contabilidade e direito de uma IES do Oeste de Santa Catarina, para realizarem suas atividades de ensino e de trabalho. Para a efetivação do objetivo geral, seus objetivos específicos são: levantar o perfil sócio econômico dos estudantes trabalhadores; conhecer as ambições destes estudantes após a conclusão do ensino superior; e identificar as dificuldades dos estudantes para conciliarem as atividades laborais e os estudos no ensino superior.

Justifica-se a opção por estudantes desses cursos, pois eles concentram a maior participação de estudantes que estudam e trabalham, mesmo que as jornadas de trabalho sejam parciais. Segundo Cardoso e Sampaio (1994), a área das Ciências Sociais Aplicadas, além de concentrar o maior percentual de estudantes trabalhadores, apresenta um leque mais amplo de ocupações.

\section{REVISÃO BIBLIOGRÁFICA}




\section{DESAFIOS DOS ESTUDANTES TRABALHADORES DE CURSOS DE ADMINISTRAÇÃO, CONTABILIDADE E DIREITO DE UMA INSTITUIÇÃO DE ENSINO SUPERIOR DO OESTE CATARINENSE}

Andrade e Sposito (1986) destacam que a demanda por cursos superiores aumentou significativamente nos últimos anos, principalmente em decorrência da democratização do acesso a esse nível de ensino no País. Para isso, o ensino superior noturno foi concebido pelas políticas educacionais como estratégia de acesso a esse nível para estudantes que trabalham (BITTAR; ALMEIDA; VELOSO, 2008). Peleias et al. (2008) afirmam que a oferta de curso superior noturno é a solução para que muitos possam frequentar o ensino superior.

As medidas de democratização possibilitaram a estudantes de diferentes classes sociais o acesso ao ensino superior, o que levou ao aumento das possibilidades de ingresso dos estudantes que trabalham, já que estes podem optar por cursos oferecidos em período diurno e/ou noturno, em instituições com diferentes perfis. Abramovicz (1990 apud PELEIAS et al., 2008) identificou em seu estudo que, apesar de um curso superior nem sempre permitir grande ascensão profissional e financeira, ele cria possibilidades para proporcionar a ascensão social dos estudantes.

A formação superior e o trabalho passaram a assumir certa complementaridade, principalmente após as transformações ocorridas no sistema de ensino superior no Brasil (CARDOSO; SAMPAIO, 1994). Esses autores constatam que as razões para o trabalho de estudantes trabalhadores não podem ser atribuídas de forma limitada às suas condições socioeconômicas. A relação estudo-trabalho é necessária para os dias atuais, considerando as demandas de conciliação da manutenção dos estudos, da busca de independência financeira e, ainda, de auxílio financeiro à família (MODESTO, 2012). Essas transformações, por um lado, resultam, mesmo que parcialmente, do processo da democratização da educação no País, o qual contribuiu para trazer o estudante que trabalha para dentro da universidade (CARDOSO; SAMPAIO, 1994), e, por outro lado, decorrem de necessidades de jovens que ainda não possuem formação específica e se veem obrigados a enfrentar o mercado de trabalho, muitas vezes ainda despreparados para ele (MODESTO, 2012).

\subsection{Ensino Superior noturno}

Desde a sua formação, a universidade apresentou-se como um lugar para desenvolvimento do conhecimento, mas também como formadora de mão de obra qualificada (CARDOSO; SAMPAIO, 1994). Para Scoz e Ito (2013), além da relevância na inserção dos sujeitos na sociedade por meio da ampliação da compreensão do mundo, o ensino superior nas sociedades contemporâneas tem a função de formação para o universo do trabalho. As autoras opinam que o ensino superior "[...] tornou-se estratégia para o desenvolvimento e a modernização das sociedades." (SCOZ; ITO, 2013, p. 74-75).

O processo de educação do homem foi fundamental para o desenvolvimento dos grupos sociais e de suas respectivas sociedades. A educação possibilita a pessoa tomar consciência de si própria, do meio que a envolve e do papel social que lhe cabe no mundo do trabalho e na comunidade (DELORS et al., 2006). Principalmente nos dias atuais, é fundamental estar preparado e ter conhecimento para enfrentar um mercado de trabalho em constante mutação. Para Oliveira (2011), a falta de estudos proporciona poucas chances de se manter no mercado de trabalho, com uma ocupação profissional que assegure satisfação e remuneração condigna.

Por conta disso, muitas pessoas, de diferentes idades, têm buscado a formação no ensino superior. Delors et al. (2006) afirmam que em qualquer sociedade, o ensino superior é um dos propulsores do desenvolvimento econômico e, ao mesmo tempo, um dos centros da educação ao longo de toda a vida. 


\section{DESAFIOS DOS ESTUDANTES TRABALHADORES DE CURSOS DE ADMINISTRAÇÃO, CONTABILIDADE E DIREITO DE UMA INSTITUIÇÃO DE ENSINO SUPERIOR DO OESTE CATARINENSE}

Diante disso, a busca pelos estudos noturnos tem se tornado cada vez mais frequente, visto que muitos precisam trabalhar para conseguir estudar. Os estudantes veem no trabalho, além do retorno financeiro, a possibilidade de desenvolver as exigências de um perfil multiprofissional, sua identidade e a conquista da maturidade pessoal, diante das situações de imprevisibilidade das organizações atuais (GONDIM, 2002).

O ensino noturno no Brasil teve início em 1860 na Escola São Bento, no Maranhão, e seu foco era a educação de adultos, para que eles pudessem "compreender melhor seus direitos e deveres." (TERRIBILI FILHO; BARREIRO, 2013; TERRIBILI FILHO; NERY, 2009). Segundo Paiva (2003 apud TERRIBILI FILHO; NERY, 2009) e Terribili Filho e Barreiro (2013), novas escolas noturnas foram criadas na maioria das províncias do Império, chegando a totalizar 117 escolas em 1876, com os objetivos de alfabetização, divulgação de direitos e deveres, profissionalização, entre outros. Tais escolas, no entanto, não sobreviveram em razão da baixa valorização a elas atribuída na época.

De acordo com o censo educacional do Instituto Nacional de Estudos e Pesquisas Educacionais (INEP) de 2018, 58,6\% dos alunos universitários frequentavam o ensino noturno. A Lei n. 9.394/1996, que trata das Diretrizes e Bases da Educação Nacional (LDB), estabelece no artigo $4^{\circ}$, inciso VI, a "oferta de ensino noturno regular, adequado às condições do educando." (BRASIL, 1996). No entanto, nas IES públicas federais, somente $30,5 \%$ dos estudantes estavam matriculados nesse turno, enquanto nas IES privadas essa participação era de $68,2 \%$, representando $81,7 \%$ do total dos estudantes matriculados no turno noturno (INSTITUTO NACIONAL DE ESTUDOS E PESQUISAS EDUCACIONAIS ANÍSIO TEIXEIRA, 2019).

Os estudantes de ensino superior noturno, na sua grande maioria, já estão inseridos no mercado de trabalho, quase sempre no período de oito horas diárias. O estudo à noite representa um prolongamento da jornada de trabalho por mais quatro ou cinco horas, tanto para os alunos quanto para os professores. Para Furlani (1998), o exame da escola noturna deve caminhar sempre ao lado de uma discussão de natureza política, pois as mudanças necessárias não se referem apenas aos cursos noturnos de forma isolada, mas devem ocorrer, necessariamente, na sociedade que os originou.

\subsection{Estudante trabalhador}

Furlani (1998) cunhou as expressões "estudante-trabalhador" e "trabalhadorestudante", respectivamente, para identificar os estudantes que precisam trabalhar para manter seus estudos e os estudantes que dependem da família e do trabalho e que, apesar de envolvidos com os estudos, também visam à profissão futura. Modesto (2012) e Mesquita (2010) definem o estudante trabalhador como o sujeito que estuda e trabalha focado nos estudos e em mantê-los. Por sua vez, o trabalhador estudante é aquele que trabalha e também estuda, tendo o seu foco voltado para o trabalho, enquanto seu estudo é um complemento para a ascensão laborativa, e, portanto, dedica tempo maior ao trabalho do que aos estudos. Tombolato (2005) também distingue o trabalhador estudante do estudante trabalhador, afirmando que a diferença reside no fato de o primeiro não ser custeado pela família e, muitas vezes, também colaborar no orçamento doméstico.

A classe de estudante-trabalhador é composta por pessoas que buscam nos estudos melhor qualificação para o mercado de trabalho, visto que o estudante ingressa no ensino superior buscando qualificação profissional e melhores oportunidades de empregos. Para Rodrigues (2016), nas sociedades complexas como a contemporânea, a formação para o 


\section{DESAFIOS DOS ESTUDANTES TRABALHADORES DE CURSOS DE ADMINISTRAÇÃO, CONTABILIDADE E DIREITO DE UMA INSTITUIÇÃO DE ENSINO SUPERIOR DO OESTE CATARINENSE}

trabalho é necessária, e o ensino superior constitui-se em uma forma de distinção de classe. Saviani (1991, p. 19) também afirma que "a educação é um fenômeno próprio dos seres humanos, significa afirmar que ela é, ao mesmo tempo, uma exigência do e para o processo de trabalho, bem como é, ela própria, um processo de trabalho."

Muller, Oliveira e Cegan (2015) verificaram as contribuições do curso para o desenvolvimento profissional dos estudantes, destacando aspectos voltados para a inserção no mundo do trabalho e o desenvolvimento da carreira. No mundo contemporâneo, o trabalho tem se tornado valor central, e a escolaridade, um diferencial, resultando numa busca cada vez mais frequente pelo ensino superior, contando com exigências para aqueles que se mantêm em uma dupla jornada - de trabalho e de estudo. A transformação dos processos produtivos modificou a lógica da formação acadêmica, que passou a ocorrer concomitantemente ao trabalho, incentivando a educação continuada e o aumento do número de trabalhadores estudantes entre a população estudantil (SANTOS, 2013).

\subsection{Os desafios ao estudante trabalhador}

Apesar de a relação trabalho e estudo ser relevante, o acesso dos estudantes que trabalham não garante sua permanência até a conclusão do curso, embora muitos estudantes trabalhadores, mesmo enfrentando dificuldades e a sobrecarga de trabalho e estudo, superem os desafios e concluam seus cursos. Vargas e Paula (2013) chamam atenção para o dilema entre as demandas de trabalho e as de estudos. Muitas pessoas que estudam e trabalham buscam conciliá-las da melhor forma, sejam elas pais, mães ou mesmo jovens que buscam contribuir em casa com uma renda mensal, pessoas que desejam uma vida com melhor qualidade.

A educação e as atividades profissionais interagem, e os estudantes formam um elo entre esses dois mundos, muitas vezes enfrentando dificuldades. Maier e Mattos (2016) e Siqueira (2007) destacam que a conciliação entre a vida profissional e a acadêmica caracteriza um desafio contemporâneo imposto aos estudantes. Os estudantes são impelidos a dividirem suas atenções entre as atividades voltadas à formação profissional de nível superior, as atividades laborais e os compromissos de cunho pessoal e familiar. Com diferentes significações, a conciliação entre trabalho e estudo, visando um futuro melhor, gera transtornos e desafios na vida de muitas pessoas. Siqueira (2007, p. 227) afirma que "[...] trabalhar e estudar ao mesmo tempo é uma realidade contraditória e de sobrevivência, portanto uma necessidade."

Além da necessidade da entrada precoce no mercado de trabalho, inúmeros são os obstáculos durante o percurso acadêmico no ensino superior por parte da classe trabalhadora. Entre os obstáculos destacam-se as disputas por vagas na universidade, as dificuldades para pagar as mensalidades e a conciliação entre trabalho e estudos (ALBERNAZ; FERREIRA; FRANCO, 2002). Niquini et al. (2015) identificaram que uma demanda maior no trabalho, associada a um baixo controle no trabalho, constitui um fator prejudicial ao desempenho acadêmico. Além da demanda no trabalho, o apoio social também influencia o desempenho. Em suma, os autores apuraram que "[...] estudantes universitários que percebem seu trabalho como tendo alta demanda, baixo controle e baixo apoio apresentam maior chance de ter um pior desempenho acadêmico." (NIQUINI et al., 2015, p. 377).

Peleias et al. (2008) ressaltam que muitos alunos dos cursos noturnos, em IES públicas e privadas, enfrentam problemas variados, como dificuldades financeiras, cansaço (inclusive associado ao deslocamento), dificuldades com o conteúdo de disciplinas (principalmente por estudantes que trabalham em áreas diferentes da área do 


\section{DESAFIOS DOS ESTUDANTES TRABALHADORES DE CURSOS DE ADMINISTRAÇÃO, CONTABILIDADE E DIREITO DE UMA INSTITUIÇÃO DE ENSINO SUPERIOR DO OESTE CATARINENSE}

curso), entre outros. Identificou-se, ainda, que problemas financeiros afetam o desempenho, principalmente, dos estudantes com mais de 36 anos de idade.

Maier e Mattos (2016), em trabalho com estudantes de enfermagem, evidenciaram entre as dificuldades as adversidades de natureza financeira em razão de alguns dos estudantes trabalhadores serem responsáveis pela renda familiar, as dificuldades na adequação dos horários de trabalho em razão de o curso ser de caráter integral e os problemas familiares por priorizarem trabalho e estudo, com prejuízo do tempo para os compromissos familiares.

Peleias et al. (2008), que estudaram diferentes percepções dos alunos com relação às dificuldades por eles enfrentadas em cursos noturnos de Ciências Contábeis, constataram que os estudantes que trabalhavam nas áreas relacionadas aos respectivos cursos apresentam dificuldades menores do que aqueles que atuavam em áreas diversas dos cursos. Segundo Cardoso e Sampaio (1994), estudantes de cursos das áreas das Humanidades e das Ciências Sociais Aplicadas estão engajados no mercado de trabalho, e ressaltam que os cursos dessas áreas concentram a maioria dos estudantes trabalhadores. Os cursos dessas áreas concentram um leque mais amplo de ocupações em comparação aos cursos das áreas das Ciências Exatas e das Ciências Biológicas. E, mesmo que ofertados em períodos diurnos parciais, e em IES públicas, atraem significativa parcela de estudantes que trabalham. Essa mudança também foi observada por Tombolato (2005), quando o autor constatou que mais alunos de cursos diurnos vêm gradativamente se engajando em algum trabalho.

O tempo para o estudo extraclasse faz-se necessário para garantir o desempenho acadêmico, o que é um problema para os estudantes trabalhadores, pois possuem menos tempo para se dedicar aos estudos e enfrentam maiores dificuldades para acompanhar o curso, resultando em menor rendimento acadêmico. Segundo Abrantes (2012), a conciliação entre trabalho e estudos, somada ao cansaço do dia a dia, não propicia aos estudantes trabalhadores a dedicação de tempo necessária ao percurso acadêmico. Para Furlani (1998), os estudantes trabalhadores, sobretudo do turno noturno, sujeitam-se a poucas horas de sono, alimentação deficiente, deslocamentos interurbanos, pouca ou quase nenhuma disponibilidade para estudos e condições de trabalho inadequadas para a troca de ideias e materiais de estudos. Apesar de estudantes citarem que o curso superior proporcionaria uma condição social e econômica melhor do que a condição de seus familiares, a maioria apontou a falta de tempo para os estudos, a realização de trabalhos acadêmicos e a troca de ideias com seus pares.

Dessa forma, é necessário criar estratégias e metodologias para que esses alunos consigam concluir suas graduações ao mesmo tempo em que dedicam considerável parte de seu tempo ao trabalho. Para Abrantes (2012), os indivíduos inseridos no universo acadêmico devem, de forma responsável, ser parceiros no processo de ensino. Pucci, Oliveira e Sguissardi (1995) ressaltam a importância de se estabelecer um equilíbrio entre o mercado e as três situações sociais de jovens: os que apenas estudam, os que trabalham e estudam e os que apenas trabalham. Assim, diante das várias particularidades, cabe aqui destacar que a motivação dos professores é fundamental para o bom desempenho dos estudantes trabalhadores, pois é de responsabilidade deles formar um profissional qualificado para sua função.

Com isso, os professores devem ser os maiores aliados dos estudantes trabalhadores, colaborando para a resolução dos problemas que envolvem o trabalho e o estudo (BITTAR; ALMEIDA; VELOSO, 2008). Portanto, é fundamental que haja diálogo entre eles, para que os estudantes trabalhadores possam ser incluídos no meio 


\section{DESAFIOS DOS ESTUDANTES TRABALHADORES DE CURSOS DE ADMINISTRAÇÃO, CONTABILIDADE E DIREITO DE UMA INSTITUIÇÃO DE ENSINO SUPERIOR DO OESTE CATARINENSE}

acadêmico sem passar por muitas dificuldades e que os professores sejam colaboradores nesse processo.

Araújo, Bridi e Motin (2009) destacam que o trabalho tanto pode ser fonte de vida quanto pode representar fonte de contradições. Ao avaliar como estudantes trabalhadores conciliam suas atividades profissionais e seus estudos, verifica-se que são muitas as dificuldades que eles enfrentam. Em razão do grande desafio que é estudar e, ao mesmo tempo, trabalhar, esses estudantes acabam recorrendo aos finais de semana e, muitas vezes, às horas das madrugadas para se adaptar à vida acadêmica e não se prejudicar ao longo dessa dupla jornada. Siqueira (2007) enfatiza a necessidade de flexibilização da escola, facilitando as condições aos alunos para que possam conciliar trabalho e estudos. A abertura ao diálogo, nessas condições, facilita a inserção do estudante trabalhador no mundo acadêmico, independentemente do trabalho ao qual esteja vinculado.

\section{PROCEDIMENTOS METODOLÓGICOS}

O objeto de estudo do presente projeto compreende a identificação dos desafios dos estudantes dos Cursos de Administração, Contabilidade e Direito de uma IES do Oeste Catarinense, que também trabalham. A população é constituída de 5.359 estudantes matriculados no primeiro semestre de 2019 nos três cursos, dos quais 80\% possuem ocupação laboral como empregados ou estagiários em empresas ou organismos públicos e privados. A amostra deste estudo foi obtida por conveniência e por acessibilidade, envolvendo os três cursos da IES.

Para o desenvolvimento deste projeto foram utilizadas as abordagens metodológicas da pesquisa qualitativa, em razão da natureza fenomenológica para a identificação dos desafios relacionados às jornadas de trabalho e estudo. Também foram utilizadas as abordagens quantitativas com vistas às quantificações de aspectos relacionados aos desafios da dupla jornada de trabalho e estudo.

Quanto aos objetivos, caracteriza-se como pesquisa exploratória, tendo em vista a busca de maiores informações relacionadas ao objeto em estudo (GIL, 2010). A pesquisa exploratória objetiva familiarizar-se com o fenômeno ou obter novas percepções deste e identificar novas percepções (ANDRADE, 2010). Também se caracteriza como pesquisa descritiva, visto que busca descrever os desafios dos estudantes para o desempenho de suas atividades laborativas e para o desenvolvimento das atividades relacionadas a seus estudos, buscando a relação entre tais desafios (GIL, 2010). Quanto aos procedimentos, caracteriza-se como levantamento tipo survey.

Os dados primários foram coletados por meio de questionário semiestruturado, formulado com base em estudos de Abrantes (2012), Bittar, Almeida e Veloso (2008), Gondim (2002), Maier (2016), Modesto (2012), Peleias et al. (2008), entre outros. O questinário foi enviado por meio eletrônico com a utilização da ferramenta Google docs, cujo endereço foi enviado por e-mail a todos os estudantes que estavam matriculados em um dos três cursos em março de 2019, dos quais retornaram 227 questionários respondidos, sendo 62 de estudantes do Curso de Administração, 118 de estudantes do Curso de Ciências Contábeis e 47 de estudantes do Curso de Direito. Os dados secundários foram extraídos de bases de dados disponibilizadas pela IES e bases do INEP.

Os dados coletados foram tabulados e ordendos em planilha eletrônica do Excel para possibilitar sua análise com base na fundamentação teórica e documental. Para as análises utilizaram-se as técnicas de estatística descritiva para os dados quantitativos e a análise de conteúdo para questões e observações de natureza qualitativa.

\section{APRESENTAÇÃO E DISCUSSÃO DOS RESULTADOS}




\section{DESAFIOS DOS ESTUDANTES TRABALHADORES DE CURSOS DE ADMINISTRAÇÃO, CONTABILIDADE E DIREITO DE UMA INSTITUIÇÃO DE ENSINO SUPERIOR DO OESTE CATARINENSE}

Nesta seção são apresentados e discutidos os resultados da pesquia. Inicialmente são apresentados os dados do perfil dos estudantes objeto deste estudo, compreendendo faixa etária, gênero, escolaridade e renda. Também se levantam as caracterizações relacionadas ao curso frequentado. Em seguida são descritas as relações entre o trabalho e os estudos, em que se evidenciam as condições para os estudos sob os aspectos conciliatórios entre trabalho e estudo, além das condições financeiras dos estudantes.

\subsection{Perfil dos estudantes}

Os Cursos de Administração e de Ciências Contábeis são ofertados somente no período noturno, e o Curso de Direito é ofertado nos períodos matutino e noturno. Dos estudantes respondentes deste Curso, $40 \%$ estudam no período matutino, e os demais no período noturno. Entre os estudantes respondentes, $77 \%$ são do sexo feminino. Quanto à faixa etária, $81 \%$ têm até 24 anos, $12 \%$ têm entre 25 e 29 anos, e $7 \%$ têm 30 anos ou mais. Quanto à residência, 55\% moram com os pais, $21 \%$ moram com outros familiares ou parentes, $19 \%$ moram sozinhos, e $2 \%$ moram com colegas. A Tabela 1 apresenta a distribuição da amostra por sexo, faixa etária e residência.

Tabela 1 - Distribuição da amostra por sexo, residência e faixa etária

\begin{tabular}{|c|c|c|c|c|c|c|}
\hline \multirow{2}{*}{$\begin{array}{l}\text { Sex } \\
\text { o }\end{array}$} & \multirow{2}{*}{ Reside } & \multicolumn{4}{|l|}{ Faixa etária } & \multirow[b]{2}{*}{ - Total } \\
\hline & & Até 19 anos & De 20 a 24 anos & De 25 a 29 anos & 30 anos ou + & \\
\hline \multirow{5}{*}{ 苂 } & Sozinho & 5 & 24 & 2 & 2 & 33 \\
\hline & Com os pais & 39 & 41 & 6 & 1 & 87 \\
\hline & Com familiares/parentes & 7 & 17 & 8 & 9 & 41 \\
\hline & Com colegas & 4 & 6 & 1 & 0 & 11 \\
\hline & Subtotal & 55 & 88 & 17 & 12 & 172 \\
\hline \multirow{5}{*}{ 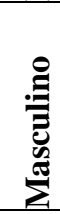 } & Sozinho & 0 & 5 & 3 & 2 & 10 \\
\hline & Com os pais & 11 & 22 & 4 & 0 & 37 \\
\hline & Com familiares/parentes & 0 & 3 & 2 & 2 & 7 \\
\hline & Com colegas & 0 & 0 & 1 & & 1 \\
\hline & Subtotal & 11 & 30 & 10 & 4 & 55 \\
\hline \multirow{5}{*}{ ڤ્ڤ } & Sozinho & 5 & 29 & 5 & 4 & 43 \\
\hline & Com os pais & 50 & 63 & 10 & 1 & 124 \\
\hline & Com familiares/parentes & 7 & 20 & 10 & 11 & 48 \\
\hline & Com colegas & 4 & 6 & 2 & 0 & 12 \\
\hline & Total & 66 & 118 & 27 & 16 & 227 \\
\hline
\end{tabular}

Os resultados quanto ao sexo e à idade neste estudo confirmam os resultados do Censo Educacional de 2018 do INEP (INSTITUTO NACIONAL DE ESTUDOS E PESQUISAS EDUCACIONAIS ANÍSIO TEIXEIRA, 2019), o qual apurou que 57\% dos estudantes matriculados são do sexo feminino e que 51,4\% têm até 24 anos. Nas IES municipais, em cuja categoria administrativa se insere a IES objeto deste estudo, os resultados são semelhantes: $57 \%$ dos estudantes matriculados são do sexo feminino, e $67,8 \%$ têm até 24 anos.

Quanto ao local de residência, 60\% dos estudantes consultados residem na mesma cidade em que estuda, cuja distância média até o local dos estudos é de 4,8 km. Os demais estudantes (40\%), residentes em outra cidade, estão a uma distância média de 34,3 km. $\mathrm{Na}$ Tabela 2 demonstram-se as frequências por faixa de distância entre a cidade de suas residências e o local de seus estudos. 


\section{DESAFIOS DOS ESTUDANTES TRABALHADORES DE CURSOS DE ADMINISTRAÇÃO, CONTABILIDADE E DIREITO DE UMA INSTITUIÇÃO DE ENSINO SUPERIOR DO OESTE \\ CATARINENSE}

Tabela 2 - Distância entre local de residência e local dos estudos (em km)

\begin{tabular}{lcccccccc}
\hline \multirow{2}{*}{ Local de sua residência } & \multicolumn{7}{c}{ Distância da IES (em $\mathbf{~ k m})$} & \multirow{2}{*}{ Total } \\
\cline { 2 - 9 } & $\mathbf{0}$ a 4,9 & $\mathbf{5}$ a 9,9 & $\mathbf{1 0}$ a 19,9 & $\mathbf{2 0}$ a 34,9 & $\mathbf{3 5}$ a 59 & Mais de 60 & \\
\hline Na cidade em que estuda & 69 & 54 & 11 & 2 & - & - & 136 \\
Em outra cidade & - & 2 & 18 & 27 & 32 & 12 & 91 \\
\hline Total & 69 & 56 & 29 & 29 & 32 & 12 & 227 \\
\hline
\end{tabular}

Fonte: os autores.

Quanto à renda informada em setembro de 2019, 58\% percebiam até R \$1.499,00, e $42 \%$ percebiam acima de $\mathrm{R} \$ 1.500,00$. Na Tabela 3 apresenta-se a distribuição das faixas de renda informada por sexo e faixa etária.

Tabela 3 - Faixas de renda informada por sexo e faixa etária

\begin{tabular}{|c|c|c|c|c|c|c|}
\hline \multirow[b]{2}{*}{ Sexo } & \multirow[b]{2}{*}{ Faixa de renda informada } & \multicolumn{4}{|l|}{ Faixa Etária } & \multirow[b]{2}{*}{ Total } \\
\hline & & Até 19 anos & De 20 a 24 anos & De 25 a 29 anos & $\begin{array}{l}30 \text { anos } \\
\text { ou }+\end{array}$ & \\
\hline \multirow{5}{*}{ 晜 } & Até R \$ 999 & 12 & 15 & 1 & 0 & 28 \\
\hline & De $R \$ 1.000$ a $R \$ 1.499$ & 33 & 34 & 4 & 2 & 73 \\
\hline & De $R \$ 1.500$ a $R \$ 2.999$ & 5 & 38 & 9 & 6 & 58 \\
\hline & $\mathrm{R} \$ 3.000 \mathrm{ou}+$ & 5 & 1 & 3 & 4 & 13 \\
\hline & Subtotal & 55 & 88 & 17 & 12 & 172 \\
\hline \multirow{5}{*}{ 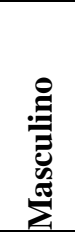 } & Até R\$ 999 & 4 & 5 & 0 & 0 & 9 \\
\hline & De $R \$ 1.000$ a $R \$ 1.499$ & 4 & 13 & 4 & 0 & 21 \\
\hline & De $R \$ 1.500$ a $R \$ 2.999$ & 3 & 11 & 3 & 2 & 19 \\
\hline & $\mathrm{R} \$ 3.000 \mathrm{ou}+$ & 0 & 1 & 3 & 2 & 6 \\
\hline & Subtotal & 11 & 30 & 10 & 4 & 55 \\
\hline \multirow{5}{*}{$\sum_{0}^{\infty}$} & Até R\$ 999 & 16 & 20 & 1 & 0 & 37 \\
\hline & De $R \$ 1.000$ a $R \$ 1.499$ & 37 & 47 & 8 & 2 & 94 \\
\hline & De $R \$ 1.500$ a $R \$ 2.999$ & 8 & 49 & 12 & 8 & 77 \\
\hline & $\mathrm{R} \$ 3.000 \mathrm{ou}+$ & 5 & 2 & 6 & 6 & 19 \\
\hline & TOTAL & 66 & 118 & 27 & 16 & 227 \\
\hline
\end{tabular}

Ao considerar as proporções de níveis de renda por gênero, verifica-se que essa relação para estudantes do sexo feminino é de $59 \%$ e $41 \%$, respectivamente, para renda com até $\mathrm{R} \$ 1.499,00$ e acima de $\mathrm{R} \$ 1.500,00$, e para os estudantes do sexo masculino é de $55 \%$ e $45 \%$, respectivamente. Esses resultados corroboram o fato de que as diferenças de rendas entre os gêneros ainda estão presentes na região.

\subsection{Relação trabalho e estudos}

Aproximadamente $95 \%$ dos estudantes consultados trabalham, e esses resultados corroboram os estudos de Cardoso e Sampaio (1994). Os autores ressaltam que os cursos das áreas das Humanidades e das Ciências Sociais Aplicadas concentram a maioria dos estudantes trabalhadores, pois possuem mais alternativas de ocupações comparativamente aos cursos das áreas das Ciências Exatas e das Ciências Biológicas. Dos estudantes que trabalham, 69\% trabalham nas mesmas áreas de seus cursos. Essa é uma condição favorável, pois estudantes que trabalham nas áreas relacionadas a seus respectivos cursos têm menos dificuldades no aprendizado (PELEIAS, et al., 2008).

Entre os estudantes que trabalham, $82 \%$ conseguem estudar até quatro horas por dia, o que caracteriza um desafio para conciliar trabalho e estudos (MAIER; MATTOS, 


\section{DESAFIOS DOS ESTUDANTES TRABALHADORES DE CURSOS DE ADMINISTRAÇÃO, CONTABILIDADE E DIREITO DE UMA INSTITUIÇÃO DE ENSINO SUPERIOR DO OESTE CATARINENSE}

2016; NIQUINI et al., 2015; SIQUEIRA, 2007). Destes, mais de 93\% estudam no período noturno, o que mostra limitadas condições de tempo para estudar. Diante dessa situação, Siqueira (2007) sugere a flexibilização dos sistemas de ensino, além de outras formas para facilitar a conciliação entre trabalho e estudos e a inserção do estudante trabalhador no ambiente acadêmico.

Para identificar as ambições dos estudantes após a conclusão do ensino superior, conforme o segundo objetivo específico deste trabalho, levantaram-se os objetivos buscados pelos estudantes por meio dos estudos. Entre os principais objetivos buscados, os estudantes indicaram que buscam a formação profissional, destacando a "Construção da vida profissional" e "Melhores oportunidades no mercado de trabalho". Esses objetivos caracterizam a formação profissional e corroboram os resultados de Modesto (2012) e a assertiva de Gondim (2002). Modesto (2012) destaca, ainda, que muitos estudantes objetivam, por vezes, o crescimento profissional. Na Tabela 4 estão os objetivos para os estudos.

Tabela 4 - Objetivos por meio dos estudos (\%)

\begin{tabular}{|c|c|c|c|c|c|}
\hline \multirow[b]{2}{*}{ O que busca com os estudos } & \multicolumn{4}{|l|}{ Faixa etária } & \multirow[b]{2}{*}{ Total } \\
\hline & Até 19 anos & $\begin{array}{l}\text { De } 20 \text { a } \\
\text { anos }\end{array}$ & $\begin{array}{c}24 \text { De } 25 \text { a } 293 \\
\text { anos }\end{array}$ & $\begin{array}{l}30 \text { anos ou } \\
+ \\
\end{array}$ & \\
\hline Melhores condições de vida & 45,5 & 61,0 & 37,0 & 31,3 & 51,5 \\
\hline Construção da vida profissional & 72,7 & 76,3 & 70,4 & 43,8 & 72,2 \\
\hline $\begin{array}{l}\text { Melhores oportunidades no mercado de } \\
\text { trabalho }\end{array}$ & 59,1 & 61,0 & 63,0 & 68,8 & 61,2 \\
\hline Prestígio & 16,7 & 11,0 & 7,4 & 12,5 & 12,3 \\
\hline Obtenção de mais conhecimento & 51,5 & 45,8 & 37,0 & 50,0 & 46,7 \\
\hline Outros & - & 1,7 & - & 6,3 & 1,3 \\
\hline
\end{tabular}

Fonte: os autores.

A busca por melhores condições de vida é o terceiro motivo que leva os estudantes consultados a buscarem o ensino superior, principalmente entre os estudantes entre $20 \mathrm{e}$ 29 anos. Esses resultados corroboram as assertivas de Bittar, Almeida e Veloso (2008) e Peleias et al. (2008). Segundo os autores, as razões para intercalar trabalho e estudos visam uma formação com diploma como um meio que possa proporcionar melhores condições de vida. Embora menos representativa, a busca de prestígio, principalmente por estudantes com até 19 anos, visa basicamente assegurar melhores condições de vida.

A busca por mais conhecimentos também é representativa entre os estudantes respondentes, cujos motivos estão relacionados aos objetivos de crescimento profissional (MODESTO, 2012). Também proporciona maiores chances de permanecer no mercado de trabalho (OLIVEIRA, 2011) e a possibilidade de desenvolvimento de um perfil multiprofissional para atender às situações imprevisíveis e às demandas das organizações (GONDIM, 2002).

Os resultados indicam que os estudantes trabalhadores buscam nos estudos os meios para melhorarem suas condições de vida, corroborando as assertivas de Modesto (2012) e Rodrigues (2016), inclusive para distinção de classe. Mas também buscam, por meio dos estudos, o crescimento profissional (MODESTO, 2012; MESQUITA, 2010). Os principais motivos apurados são apresentados na Tabela 5.

Tabela 5 - Motivos para intercalação de estudos com trabalho (\%) 


\section{DESAFIOS DOS ESTUDANTES TRABALHADORES DE CURSOS DE ADMINISTRAÇÃO, CONTABILIDADE E DIREITO DE UMA INSTITUIÇÃO DE ENSINO SUPERIOR DO OESTE CATARINENSE}

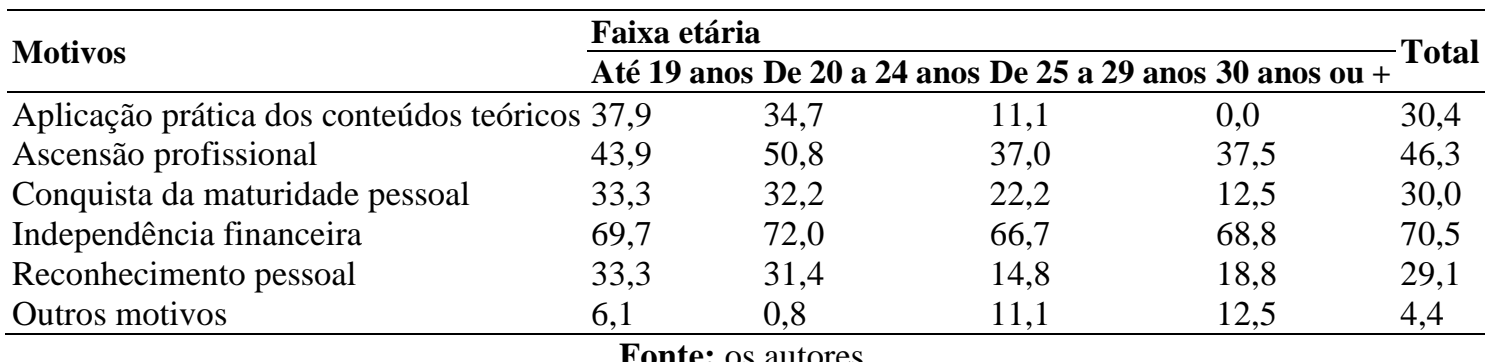

A independência financeira e o crescimento profissional são complementados por outros objetivos, como a busca de aperfeiçoamento teórico para o exercício profissional, o crescimento pessoal e o reconhecimento pessoal. Isso confirma a constatação de Santos (2013), para quem as razões que levam os estudantes a trabalhar se estendem além das condições socioeconômicas.

Com o objetivo de identificar as dificuldades dos estudantes levantaram-se as condições relacionadas ao trabalho, como a distância entre o local em que residem e a IES em que estudam, o tempo médio diário em horas dedicado aos estudos e as percepções dos estudantes. Entre os estudantes que trabalham, mais da metade afirma que não consegue estudar enquanto trabalha, e aproximadamente $37 \%$ conseguem estudar às vezes. Aqueles que conseguem estudar enquanto trabalham possuem carga horária de até quatro horas diárias e são principalmente estudantes que desenvolvem atividades de estágio remunerado. Aproximadamente $82 \%$ dos estudantes que trabalham dedicam até quatro horas diárias aos estudos. Cerca de $16 \%$ estudam entre quatro e seis horas diárias, e pouco mais de $2 \%$ estudam mais de seis horas diárias. Considere-se que o tempo dedicado aos estudos compreende o horário de aula. Apesar de se depararem com alguns desafios, aproximadamente 69\% dos estudantes trabalham nas mesmas áreas de seus cursos, e essa condição atenua as dificuldades para a conciliação das tarefas de trabalho e dos estudos (PELEIAS et al., 2008; CARDOSO; SAMPAIO, 1994).

Para este estudo, levantaram-se as percepções dos estudantes sobre as suas dificuldades relacionadas aos estudos. Para o levantamento foi utilizada a escala de 0 (zero) a 6 (seis), sendo 0 (zero) a condição menos favorável e 6 (seis) a condição ou percepção mais favorável. Na Tabela 6 apresenta-se a distribuição percentual das dificuldades percebidas.

Tabela 6 - Percepção das dificuldades, segundo a escala: $0=$ menos favorável e $6=$ mais favorável $(\%)$

\begin{tabular}{llllllll}
\hline Dificuldades percebidas & $\mathbf{0}$ & $\mathbf{1}$ & $\mathbf{2}$ & $\mathbf{3}$ & $\mathbf{4}$ & $\mathbf{5}$ & $\mathbf{6}$ \\
\hline Conciliação entre trabalho e estudo & 2,8 & 11,2 & 16,3 & 28,8 & 18,6 & 14,0 & 8,4 \\
Tempo para estudar & 7,9 & 23,3 & 27,4 & 17,2 & 14,9 & 4,7 & 4,7 \\
Estresse & 12,6 & 14,4 & 15,3 & 19,5 & 14,4 & 10,2 & 13,5 \\
Condição financeira & 4,0 & 10,6 & 12,8 & 25,1 & 20,3 & 17,2 & 10,1 \\
Despesas extras (materiais, alimentação, fotocópias, etc.) & 9,7 & 16,3 & 18,1 & 19,4 & 18,1 & 11,9 & 6,6 \\
Distância entre a universidade e sua casa & 15,2 & 16,5 & 13,9 & 17,7 & 13,9 & 12,7 & 10,1 \\
Apoio familiar & 3,5 & 4,0 & 11,9 & 9,3 & 8,4 & 11,9 & 51,1 \\
Curso atende às expectativas & 2,2 & 9,3 & 11,5 & 14,1 & 15,4 & 21,6 & 26,0 \\
Satisfação com a graduação & 4,8 & 4,8 & 10,1 & 12,3 & 18,9 & 21,6 & 27,3
\end{tabular}




\section{DESAFIOS DOS ESTUDANTES TRABALHADORES DE CURSOS DE ADMINISTRAÇÃO, CONTABILIDADE E DIREITO DE UMA INSTITUIÇÃO DE ENSINO SUPERIOR DO OESTE CATARINENSE}

Fonte: os autores.

Sobre as condições relacionadas aos estudos entre os estudantes que trabalham $30 \%$ percebem que têm alguma dificuldade na conciliação entre trabalho e estudos, $29 \%$ mostram-se indiferentes às dificuldades, e $41 \%$ percebem poucas ou nenhuma dificuldade. Por outro lado, $59 \%$ dos estudantes que trabalham indicam ter dificuldades quanto à disponibilidade de tempo para os estudos, e $42 \%$ relacionam o estresse às suas dificuldades. Dos estudantes que residem a uma distância maior que cinco quilômetros da IES, $46 \%$ apontam ter dificuldades de deslocamento relacionadas com essa distância. Os resultados apontam, portanto, que os estudantes trabalhadores se defrontam com alguns desafios típicos da vida contemporânea (MAIER; MATTOS, 2016).

A maioria percebe suas condições financeiras como indiferente e tendendo a poucas dificuldades. Mais de $71 \%$ apontam que contam com apoio familiar. A renda com o trabalho, o apoio familiar e, em muitos casos, as bolsas de estudo oferecidas pelo Programa de Bolsas Universitárias de Santa Catarina (Uniedu), fundamentado nos artigos 170 e 171 da Constituição do Estado de Santa Catarina, contribuem para a minimização das dificuldades financeiras. Mesmo assim, 44\% apontam que têm dificuldades com despesas extras, relacionadas com materiais, alimentação, fotocópias, transporte, etc.

Quanto ao curso, 63\% apontam que ele atende às suas expectativas, e aproximadamente $68 \%$ estão satisfeitos com o curso de graduação que frequentam. Porém, merece atenção o fato de $39 \%$ não estarem satisfeitos com o rendimento acadêmico. Também é preciso buscar as razões que levam alguns estudantes a não perceberem o atendimento de suas expectativas e a não se sentirem satisfeitos com o curso que frequentam. Frente a essas percepções, sobretudo entre estudantes trabalhadores, é necessário desenvolver formas de flexibilização dos processos de ensino (SIQUEIRA, 2007).

\section{CONSIDERAÇÕES FINAIS}

No contexto contemporâneo, com as mudanças socioeconômicas, culturais e políticas, os processos produtivos também passam por transformações, e, assim, as formações profissional e superior passaram a se realizar concomitantemente (MAIER; MATTOS, 2016). Esse fenômeno estimulou o aumento do número de estudantes trabalhadores (SANTOS, 2013), os quais, em razão da dupla jornada, estão sujeitos a vários desafios (VARGAS; PAULA, 2013). Este trabalho teve como objetivo a análise dos desafios dos estudantes trabalhadores dos Cursos de Administração, Contabilidade e Direito de uma IES do Oeste de Santa Catarina.

A maioria dos estudantes consultados está inserida no mercado de trabalho, caracterizando-se como estudante trabalhador (FURLANI, 1998; MODESTO, 2012). Quanto ao perfil, os estudantes são predominantemente do sexo feminino, têm até 24 anos e residem com os pais ou outros familiares; ainda, a maioria reside na mesma cidade em que estuda. Quanto à renda, a maioria percebia até R\$1.499,00 em setembro de 2019.

Entre os estudantes que trabalham, a maioria consegue estudar até quatro horas diárias e são estudantes do turno noturno. Essa condição aponta para um desafio a ser considerado pela IES no desenvolvimento dos planos político-pedagógicos e dos processos de ensino-aprendizagem.

Os estudantes buscam por meio dos estudos, principalmente, a formação profissional, as condições para obterem melhores oportunidades de trabalho e a 


\section{DESAFIOS DOS ESTUDANTES TRABALHADORES DE CURSOS DE ADMINISTRAÇÃO, CONTABILIDADE E DIREITO DE UMA INSTITUIÇÃO DE ENSINO SUPERIOR DO OESTE CATARINENSE}

possibilidade de melhorarem as condições de vida. Mas também há, entre eles, quem busca reconhecimento pessoal e prestígio social. Entre os motivos que levam os estudantes a conciliarem os estudos com o trabalho destacam-se a busca por independência financeira e a ascensão profissional. Mas há outros indicativos de que a busca pelos estudos se estende a outras razões não restritas aos fins econômicos.

As dificuldades percebidas pelos estudantes, mesmo que atenuadas, são típicas entre estudantes trabalhadores, sobretudo na contemporaneidade. Apesar disso, no tocante às condições financeiras, a maioria está indiferente ou indica ter poucas dificuldades, visto que essas condições são atenuadas pelo apoio familiar, pela renda do trabalho e por bolsas de estudo. $\mathrm{O}$ curso frequentado atende às expectativas, mas também se identifica que parte dos estudantes estão insatisfeitos com o curso e com seus rendimentos escolares. Portanto, há lacunas para o aperfeiçoamento do processo de ensino-aprendizagem por parte da IES, sobretudo para a inclusão dos estudantes trabalhadores.

Os resultados deste estudo se limitam a estudantes dos Cursos de Administração, Ciências Contábeis e Direito de uma instituição de ensino superior do Oeste Catarinense. Outra limitação dos resultados está relacionada à amostra delimitada por conveniência de acessibilidade, envolvendo três cursos da área das Ciências Sociais Aplicadas, não permitindo sua generalização a cursos de outras áreas do conhecimento. Sugerem-se, portanto, estudos que envolvam cursos de outras áreas do conhecimento, que reúnam diferentes IES e que sejam realizados em regiões diversas.

\section{REFERÊNCIAS}

ABRANTES, N. N. F. Trabalho e estudo: uma conciliação desafiante. In: FÓRUM INTERNACIONAL DE PEDAGOGIA - FIPED, 4., 2012, Campina Grande. Anais [...] Campina Grande: Realize Editora, 2012. ISSN 2316-1086. Disponível em: http://www.editorarealize.com.br/revistas/fiped/trabalhos/ed3d2c21991e3bef5e069713a f9fa6ca.pdf. Acesso em: 10 jun. 2019.

ALBERNAZ, A.; FERREIRA, F. H. G.; FRANCO, C. Qualidade e equidade no ensino fundamental brasileiro. Pesquisa e Planejamento Econômico, v. 32, n. 3, p. 453-476, 2002. ISSN 2237-2091. Disponível em: http://ppe.ipea.gov.br/index.php/ppe/article/viewFile/139/74. Acesso em: 10 jun. 2019.

ANDRADE, C. L.; SPOSITO, M. P. O aluno do curso superior noturno: um estudo de caso. Cadernos de Pesquisa, n. 57, p. 3-19, 1986. ISSN 1980-5314.

Disponível em: http://publicacoes.fcc.org.br/ojs/index.php/cp/article/view/1333/1333. Acesso em: 15 abr. 2019.

ANDRADE, M. M. Introdução à metodologia do trabalho científico: elaboração de trabalhos na graduação. 10. ed. São Paulo: Atlas, 2010. ISBN 9788522458561.

ARAÚJO, S. M.; BRIDI, M. A.; MOTIN, B. L. Sociologia: um olhar crítico. São Paulo: Contexto, 2009. ISBN 8572444378.

BITTAR, M.; ALMEIDA, C. E. M.; VELOSO, T. C. M. A. Ensino noturno e expansão do acesso dos estudantes-trabalhadores à educação superior. In: BITTAR, M.; OLIVEIRA, J.; MOROSINI, M. (org.). Educação superior no Brasil - 10 anos pós- 
LDB. Brasília, DF: Instituto Nacional de Estudos e Pesquisas Educacionais Anísio Teixeira, 2008. (Coleção INEP 70 anos, v. 2). p. 89-110. ISBN 8586260865.

BRASIL. Lei $\mathrm{n}^{\circ}$ 9.394, de 20 de dezembro de 1996. Estabelece as diretrizes e bases da educação nacional. Diário Oficial da União, Brasília, DF, 20 dez. 1996. Disponível em: http://www.planalto.gov.br/ccivil_03/leis/19394.htm. Acesso em: 12 nov. 2019.

CARDOSO, R. C. L.; SAMPAIO, H. Estudantes Universitários e o trabalho. Revista Brasileira de Ciências Sociais, v. 9, n. 26, out. 1994. ISSN 1806-9053. Disponível em: http://anpocs.com/images/stories/RBCS/26/rbcs26_03.pdf. Acesso em: 3 abr. 2019.

CARRANO, P. C. R. Jovens universitários. In: SPOSITO, M. P. (coord.). Juventude e escolarização (1980-1998). Brasília, DF: MEC/INEP, 2002. p. 135-155. ISSN 16760565 .

DELORS, J. et al. Educação: um tesouro a descobrir. 10. ed. São Paulo: Cortez, 2006. ISBN 8524906731.

FURLANI, L. M. T. A claridade da noite: os alunos do ensino superior noturno. São Paulo: Cortez, 1998. ISBN 8524906790.

GIL, A. C. Como elaborar projetos de pesquisa. 5. ed. São Paulo: Atlas, 2010. ISBN 8522458233.

GONDIM, S. M. G. Perfil profissional e mercado de trabalho: relação com formação acadêmica pela perspectiva de estudantes universitários. Estudos de Psicologia, v. 7, n. 2, p. 299-309, 2002. DOI: https://doi.org/10.1590/S1413-294X2002000200011.

Disponível em: http://www.scielo.br/scielo.php?script=sci_arttext\&pid=S1413294X2002000200011\&lng=en\&nrm=iso. Acesso em: 9 abr. 2019.

INSTITUTO NACIONAL DE ESTUDOS E PESQUISAS EDUCACIONAIS ANÍSIO TEIXEIRA. Sinopse Estatística da Educação Superior 2018. Brasília, DF: INEP, 2019. Disponível em: http://portal.inep.gov.br/web/guest/sinopses-estatisticas-da-educacaosuperior. Acesso em: 12 nov. 2019.

MAIER, S. R. O.; MATTOS, M. O trabalhar e o estudar no contexto universitário: uma abordagem com trabalhadores-estudantes. Saúde, v. 42, n. 1, p. 179-185, 2016. ISSN 22365834.

Disponível

em: https://periodicos.ufsm.br/revistasaude/article/view/20477/pdf. Acesso em: 8 abr. 2019.

MESQUITA, M. C. G. D. O trabalhador estudante do ensino superior noturno: possibilidades de acesso, permanência com sucesso e formação. 2010. Tese (Doutorado em Ciências Humanas) - Departamento de Educação, Pontifícia Universidade Católica de Goiás, Goiânia, 2010.

MODESTO, M. A. Estudante-trabalhador ou trabalhador-estudante? Nuances da relação entre educação e trabalho na UFS. In: COLÓQUIO INTERNACIONAL EDUCAÇÃO E CONTEMPORANEIDADE, 7., 2012. São Cristóvão. Anais [...] São Cristóvão, 2012. 
MULLER, R.; OLIVEIRA, V. S.; CEGAN, E. Perfil do (a) profissional de Secretariado Executivo na gestão contemporânea: evidências a partir dos ingressantes no mercado de trabalho na cidade de Curitiba, e das demandas empresariais. Revista de Gestão e Secretariado, v. 6, n. 3, p. 129-151, set./dez. 2015. ISSN 2178-9010. Disponível em: https://www.revistagesec.org.br/secretariado/article/view/453/pdf. Acesso em: 8 abr. 2019.

NIQUINI, R. P. et al. Características do trabalho de estudantes universitários associadas ao seu desempenho acadêmico. Educar em revista, v. 31, n. 1, p. 359-381, 2015. DOI: https://doi.org/10.1590/0102-4698122477.

OLIVEIRA, J. F.; BITTAR, M.; LEMOS, J. R. Ensino Superior noturno no Brasil: democratização do acesso, da permanência e da qualidade. Revista de Educação Pública, v. 19, n. 40. p. 247-268, 2010. ISSN 01045962.

OLIVEIRA, M. A. G. O novo mercado de trabalho. Guia para iniciantes e sobreviventes. 8. ed. Rio de Janeiro: Editora Senac Rio, 2011. ISBN 857756097X.

PELEIAS, I. R. et al. Pesquisa sobre a percepção dos alunos do $1^{\circ}$. ano de Ciências Contábeis na Cidade de São Paulo em Relação às Dificuldades por eles percebidas no período noturno. Revista Universo Contábil, , v. 4, n. 1, p. 81-94, jan./mar. 2008. ISSN 1809-3337.

PUCCI, B.; OLIVEIRA, N. R.; SGUISSARDI, V. O ensino noturno e os trabalhadores. 2. ed. São Carlos: EDUFSCar, 1995. ISBN 8585173068.

RODRIGUES, G. M. C. Desafios à formação e perspectivas profissionais de trabalhadores-estudantes e estudantes- trabalhadores do curso de pedagogia. 2016. Dissertação (Mestrado em Educação) - Programa de Pós-graduação Stricto Sensu em Educação, Pontifícia Universidade Católica de Goiás, 2016. Disponível em: http://tede2.pucgoias.edu.br:8080/bitstream/tede/3531/2/GEOVANNA\%20MOREIRA \%20CALES\%20RODRIGUES.pdf. Acesso em: 15 abr. 2019.

SANTOS, B. S. Pela mão de Alice: o social e o político na pós-modernidade. 14. ed. São Paulo: Cortez, 2013. ISBN 8524920327.

SAVIANI, D. Pedagogia histórico-crítica: primeiras aproximações. São Paulo: Cortez, Autores Associados, 1991. ISBN 8585701099.

SCOZ, B. J. L.; ITO, M. C. R. Ensino superior e psicopedagogia: a busca por uma graduação alinhada com a contemporaneidade. Psicopedagia, v. 30, n. 91, p. 7476, 2013. ISSN 0103-8486. Disponível em: http://pepsic.bvsalud.org/scielo.php?script=sci_arttext\&pid=S010384862013000100009\&lng=pt\&nrm=iso. Acesso em 12 nov. 2019.

SIQUEIRA, J. F. A realidade contraditória e de sobrevivência do jovem trabalhador e estudante nas escolas estaduais de Porto Alegre/RS/Brasil. Revista de Estudios y Experiencias en Educación, v. 1, p. 84-113, 2007. ISSN 0718-5162. Disponível em: http://www.rexe.cl/ojournal/index.php/rexe/article/view/308/314. Acesso em: 29 abr. 2019. 
TERRIBILI FILHO, A.; BARREIRO, I. M. F. O ensino superior noturno no Brasil: história, crescimento e políticas públicas no início do século XXI. Revista Iberoamericana de Educación, v. 62, n. 3, p. 1-14, 2013. ISSN 1681-5653. DOI: https://doi.org/10.35362/rie623818

TERRIBILI FILHO, A.; NERY, A. C. B. Ensino superior noturno no Brasil: história, atores e políticas. Revista Brasileira de Política e Administração da Educação, v. 25, p. 61-82, 2009. ISSN 2447-4193. Disponível em: https://seer.ufrgs.br/rbpae/article/view/19327/11227. Acesso em: 12 nov. 2019.

TERRIBILI FILHO, A.; QUAGLIO, P. O cenário urbano para o estudante do ensino superior noturno na cidade de São Paulo: triste realidade ou palco de heróis? Millenium, v. 31, p. 74-87, 2005. ISSN 08733015.

TOMBOLATO, M. C. R. Qualidade de vida e sintomas psicopatológicos do estudante universitário trabalhador. 2005. Dissertação (Mestrado em Psicologia) - Programa de Pós-graduação em Psicologia, Pontifícia Universidade Católica de Minas Gerais, Belo Horizonte, 2005.

VARGAS, H. M.; PAULA, M. F. C. A inclusão do estudante-trabalhador e do trabalhador-estudante na educação superior: desafio público a ser enfrentado. Avaliação: Revista da Avaliação da Educação Superior, v. 18, p. 459-485, 2013. ISSN 14144077. DOI: http://dx.doi.org/10.1590/S1414-40772013000200012. 